九州大学学術情報リポジトリ

Kyushu University Institutional Repository

\title{
Characteristic of Equatorial Pc5 at ILE-IFE
}

Fujimoto, Akiko

Department of Earth and Planetary Sciences, Graduate School of Science, Kyushu University

Joshua, Emmanuel 0

Department of Physics, University of Ibadan

Abe, Shuji

Space Environment Research Center, Kyushu University

Yumoto, Kiyofumi

Space Environment Research Center, Kyushu University

https://doi.org/10.5109/11813

出版情報: 九州大学大学院理学研究院紀要 : Series D, Earth and planetary sciences. 32 (1)， pp. 25-30, 2008-02-01. Faculty of Science, Kyushu University

バージョン :

権利関係 : 
Mem. Fac. Sci., Kyushu Univ., Ser. D, Earth \& Planet. Sci., Vol. XXXII, No. 1, pp. 25-30, February 1, 2008

\title{
Characteristic of Equatorial Pc5 at ILE-IFE
}

\author{
Akiko Fujimoto*, Emmanuel O. Joshua ${ }^{* *}$, Shuji $\mathrm{Abe}^{* * *}$ and Kiyohumi Yumoto ${ }^{* * *}$
}

\begin{abstract}
In order to clarify characteristics of equatorial Pc5 pulsations for seasonal and magnetospheric activity variation ( $\mathrm{Kp}$ index to evaluate magnetospheric disturbance), we analyzed geomagnetic field data obtained from Ile-Ife Station in Nigeria. We found that the dayside equatorial Pc5 has high occurrence during equinox period in comparison to solstice periods. The occurrence of dayside equatorial Pc5 depends on season variation, while it is indecisive for relationship between equatorial Pc5 and Kp index. Also the amplitude, period, and duration of equatorial Pc5 have no dependence on both seasonal variation and Kp index.
\end{abstract}

Keywords: Pulsation, Kp index, Equatorial, Pc5

\section{Introduction}

Pc5 pulsation in frequency band between 1.67 and $6.67 \mathrm{mHz}$ is primarily observed at high latitude (e.g., the auroral oval), often after an interval of geomagnetic disturbances. The amplitude of ground-based Pc5 at high latitude is typically larger than several tens nanoteslas (see Saito, 1969). The duration of high-latitude Pc5 wave lasts several hours, and there is also damping within 10 minutes. Several previous studies have suggested some generation mechanisms for Pc5 at high latitudes, field line resonances driven by Kelvin-Helmholtz instability, magnetosphere cavity and waveguide modes (Southwood, 1968, 1974; Chen and Hasegawa, 1974; Samson et al., 1992).

Pc5 pulsations are also observed at mid and low latitudes (Ziesolleck and Chamalaun, 1993) and equatorial latitudes (Saito, 1969; Reddy et al., 1994) as well as high latitudes. There is evidence that the equatorial Pc5 amplitudes are enhanced during dayside in comparison to mid-low latitudes (Trivedi et al., 1997). They suggested that the equatorial dayside enhanced Pc5 is produced by ionospheric conductivity due to the Cowling effect (Kikuchi and Araki, 1979) who proposed a generation mechanism of the equatorial dayside enhanced sudden commencement (SC) disturbance caused by that an instantaneous transmission of polar ionospheric electric fields into the equatorial ionosphere. Reddy et al. (1994) found that the ground-based Pc5 was associated with the electric field measured by the coherent backscatter radar at the dayside dip equator.

While characteristics of the equatorial dayside Pc5 is not yet clearly understood for seasonal variation and magnetosphere magnetic disturbance. This paper reports morphological features of

Manuscript received on 27 November 2007; accepted on 20 December 2007

* Department of Earth and Planetary Sciences, Graduate School of Science, Kyushu University, 53, 6-10-1 Hakozaki Higashi-ku Fukuoka, 812-8581, JAPAN; fujimoto@geo.kyushu-u.ac.jp

** Department of Physics, University of Ibadan, NIGERIA

*** Space Environment Research Center, Kyushu University, 53, 6-10-1 Hakozaki Higashi-ku Fukuoka, 812-8581, JAPAN 
Pc5 geomagnetic pulsation (occurrence, amplitude and period) observed at Ile-Ife which is an equatorial station located south of the dip equator in Nigeria, using geomagnetic field data from January 1986 to December 1989.

\section{Data set}

In this study we analyze flux-gate magnetometer data observed at Ile-Ife Station (latitude: $7.55^{\circ} \mathrm{N}$, longitude: $4.55^{\circ} \mathrm{E}$ geographic coordinates, and geomagnetic latitude: $2.88^{\circ} \mathrm{S}$ ) operated during a magnetic survey of South-Western Nigeria (Ogunade, 1987). The geomagnetic field variations were traced as $\mathrm{H}$ (geographic north-south), D (geographic east-west) and Z (vertical). We analyzed the Ile-Ife magnetometer data during the period of 1986 January 1 to 1989 December 31 and found 198 Pc5 pulsation events. One problem of this study is that the data are not complete. The data in 1986 and 1989 are available for one whole year. However, that in 1987 and 1988 are available only for four months each of these years. In order to classify a magnetic disturbance as a Pc5 event we required that it has (1) an amplitude of greater than $0.5 \mathrm{nT}$, (2) a frequency in the Pc5 range (1.67$6.67 \mathrm{mHz}$ ), and (3) at least an completed cycle. Each Pc5 event is classified individual occurrence local time (LT) sector (if one Pc5 event begins between 1000 and 1100 LT, this Pc5 is classified 1000 LT event). We clarified Pc5 characteristics in terms of occurrence, amplitude, period, and duration.

\section{Characteristics of Pc5}

In order to declare the Pc5 characteristic for seasonal variation, one year is divided into three seasons: June Solstice (May, June, July, August), Equinoxes (March, April, September, October), and December Solstice (November, December, January, February). In this paper, they are represented by letters J, E and D, respectively. Also, in order to indicate the effect of magnetic activity for Pc5 characteristics, all Pc5 events are grouped by Kp index. The Kp index is separated; $\mathrm{Kp}<1+, 2-<\mathrm{Kp}<2+, 3-<\mathrm{Kp}<3+, 4-<\mathrm{Kp}<4+, 5-<\mathrm{Kp}<5+, 6-<\mathrm{Kp}$.

The Pc5 occurrence for the entire period (1986-1989) shows a peak around dawn-to-noon sector (Fig. 1a). The occurrence for each magnetic filed H, D and $\mathrm{Z}$ component is 119, 23 and 56 events, respectively. For all the seasons, maximum occurrence of Pc5 coincides with the maximum occurrence for the entire period. Equinoctial dayside Pc5 occurs more than other seasons, and June solstice has a minimum occurrence. We found seasonal occurrence dependence of the equatorial Pc5. However, the Pc5 occurrence did not show any dependence on Kp index (see Fig. 2a).

The amplitude, period, and duration do not depend for all seasons and all Kp index (Fig. 1b-c, Fig. 2b-c, the duration is not shown). The average amplitude of equatorial Pc5 as H, D and Z component is $12.5 \mathrm{nT}, 5.9 \mathrm{nT}$, and $11.2 \mathrm{nT}$, respectively. In addition, Pc5 amplitude during dawnto-noon sector is enhanced in comparison to dusk-to-midnight sector, and the value of maximum Pc5 amplitude H, D and $\mathrm{Z}$ component are $50 \mathrm{nT}, 45 \mathrm{nT}$, and $16 \mathrm{nT}$, respectively. The average frequency of Pc5 for the entire period of 1986-1989 is found to be between $2.1 \mathrm{mHz}$ and $2.8 \mathrm{mHz}$, also tends to be short around local noon and long around dusk and dawn sector. The duration of equatorial Pc5 is between a few and 40 minutes and the average duration is about 14 minutes. Most of the equatorial Pc5 events have small wave-number about three. This feature indicates that the equatorial Pc5 at Ile-Ife tended to be pulse waves. 


\section{Seasonal Variation}
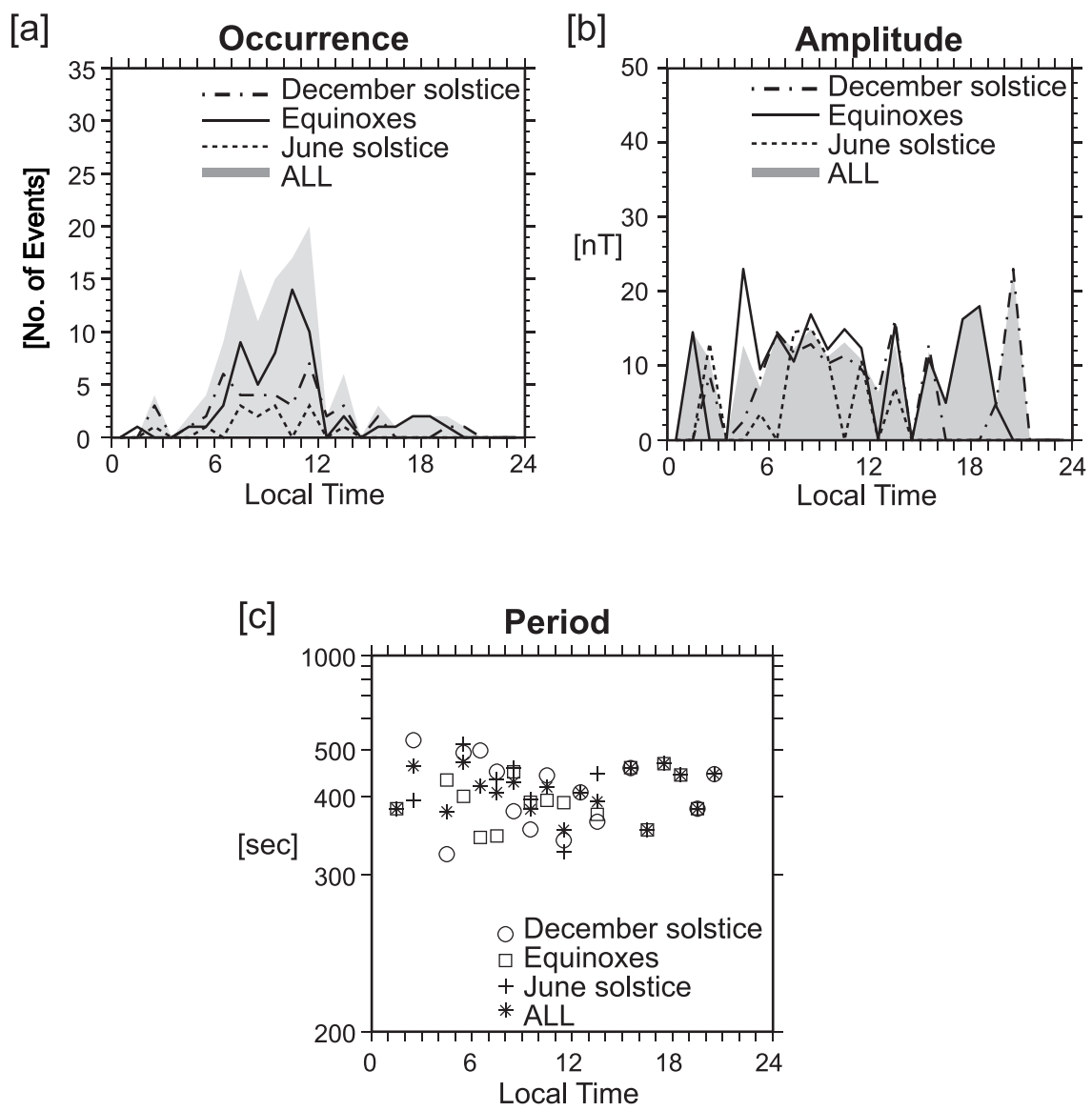

Fig. 1. Pc5-seasonal variation. June Solstice (May, June, July, August); Equinoxes (March, April, September, October) and December Solstice (November, December, January, February): [a] Pc5 occurrence for LT; [b] average Pc5 amplitude for LT; and [c] average Pc5 period.

\section{Summary and Discussion}

In this paper, we have analyzed equatorial Pc5 at Ile-Ife Station in Nigeria during 1986-1989. We can summarize the results as follows:

(1) Occurrence of dayside equatorial Pc5 is enhanced during Equinoxes in comparison to June and December Solstice, while there is no dependence for Kp index.

(2) The amplitude, period, and duration are not related to both seasonal variation and Kp index.

(3) The dawn-to-noon enhanced Pc5 shows H-comp. and Z-comp. amplitudes larger than D-comp. amplitude.

(4) The frequency around local noon is shorter than dusk and dawn sector.

(5) The observed pulsations seem to be nearly pulse type. 


\section{Kp index Variation}

[a]

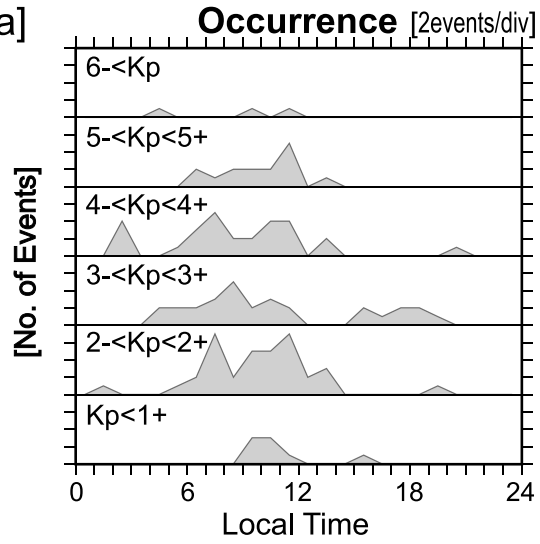

[b]

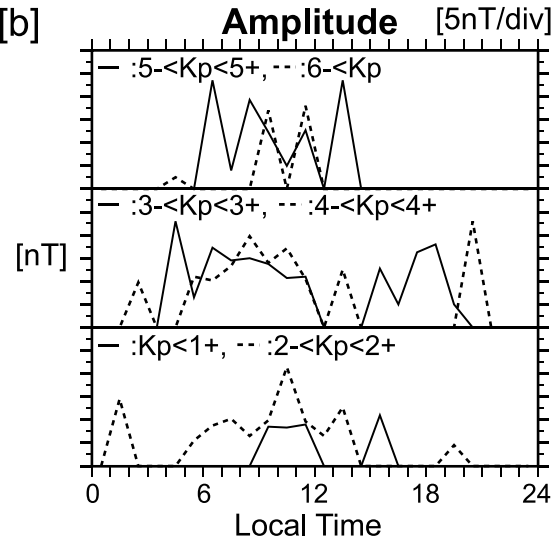

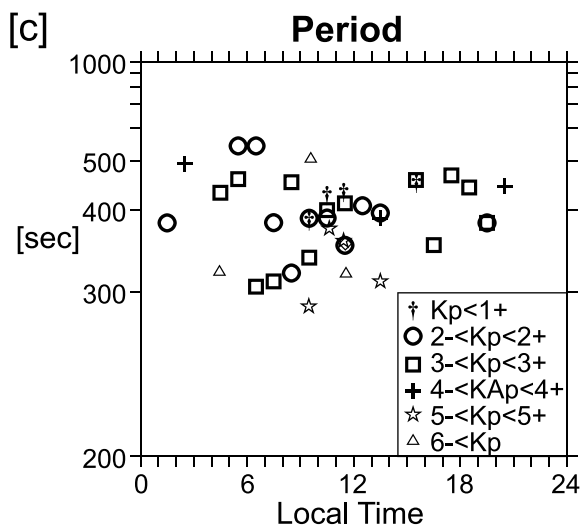

Fig. 2. Pc5-Kp index variation. Kp Index is separated as follows: $\mathrm{Kp}<1+, 2-<\mathrm{Kp}<2+, 3-<\mathrm{Kp}<3+, 4-<\mathrm{Kp}<4+, 5-$ $<\mathrm{Kp}<5+, 6-<\mathrm{Kp}$ : [a] Pc5 occurrence for LT; [b] average Pc5 amplitude for LT; and [c] average Pc5 period.

Russell and McPherron (1973) suggested that a semi-annual variation in the effective southward component of interplanetary field (IMF) causes a seasonal variation in geomagnetic activity. Considering the concept of southward IMF, the Russell-McPherron effect combines the fundamental ideas of axial hypothesis (on the annual variation in the angle between the solar axis and the ecliptic: Priester and Cattani, 1962) and equinoctial hypothesis (on the seasonal variation in the orientation of the Earth's axis of rotation relative to the Earth-Sun line: Bartles, 1932). The semi-annual variation of Pc5 at high latitudes is referred as the basic idea of a seasonal variation of equatorial Pc5. Rao and Gupta (1987) clarified that the occurrence of high-latitude Pc5 $(\mathrm{L} \approx 8)$, which has diurnal variation, maximized during the equinoxes among the three Lloyds' seasons. They suggested that this semi-annual variation of Pc5 parameters may have resulted from the variations in the inclination of the Earth's rotational axis with respect to the Sun-Earth line during the course of a year in accordance with Bartels' equinoctial hypothesis. Hence, though there is no unambiguous reason 
why the dayside equatorial Pc5 has high occurrences during equinoxes, the seasonal variation of equatorial Pc5 seems to be related to Russell-McPherron effect. Now we introduce RussellMcPherron effect into the generation mechanism of diurnal equatorial Pc5. A seasonal variability of magnetospheric form can be reflected as latitudinal shifts in the electrojet axis and/or seasonal variability in electrojet intensity. This implies that the varying configuration of the magnetosphere can lead to the additional influence for the Kikuchi and Araki model.

The dayside equatorial Pc5 is believed to be attributed to the enhancement effect of Equatorial Electrojet current. Reddy et al. (1994) reported that the equatorial Pc5 was coherently observed with the high-latitude Pc5. They suggested that the equatorial Pc5 oscillation was caused by a Pc5related polar electric field transmitted to the Equator. The result of Reddy et al. (1994: i.e., the ionospheric westward current induced by an incidence of the compressional mode causes a shielding effect on the propagating waves) indicated that the equatorial enhancement is a direct effect of the global compressional mode propagating to the equatorial ionosphere across field lines. On the other hand, the result mentioned in the summary (5) (i.e., almost all Pc5 in this paper seem to be pulse type) may be caused by the ionospheric penetrator mechanism from the Kikuchi and Araki (1979) model. Motoba et al. (2002) found that the afternoon Pc5 from the auroral to equatorial latitudes were nearly in phase, which was consistent with the phase structure of the main impulse (MI) of SC events, and they proposed the scenario of the global Pc5 excitation that fit the SC model (Araki, 1994). The equatorial Pc5 enhanced around local noon (in this paper) may be associated with such a mechanism.

We want to explain why dayside equatorial Pc5 occurs more often during equinoxes than during other times of the year. However, it is difficult to determine the mechanism of how this semi-annual Pc5 is generated and propagated because the occurrence of Pc5 depends on a variety of factors (such as latitude, local time, and season, in the case of ground observation; see Saito, 1969) and also the state of the solar wind (which is one source of Pc5). Therefore, it is necessary to analyze more the situation of dayside equatorial Pc5 to achieve our goal. Specially, the following must be done:

(1) Understand the relationships of Pc5s occurring at different latitudes (high, middle, low, and equatorial) at different local times, thereby establishing the clear description of the spatial distribution of Pc5 modes.

(2) Understand the relationship between Pc5 of various latitudinal regions and various solar wind parameters (velocity, IMF variation, seasonal variation), thereby establishing the source and generation mechanism (i.e., Kelvin-Helmholtz instability, drifting wave, compressional mode, etc.) of equatorial Pc5 pulsations.

(3) Clarify the propagation mode of the equatorial Pc5.

\section{Acknowledgments}

Kp index is provided by WDC for Geomagnetism, Kyoto, and Geo Forschungs Zentrum Potsdam (GFZ) as the data suppliers. We thank the critical comments provided by the reviewer. This work is supported in part by NICT (the National Institute of Information and Communications Technology) Space Weather Project. 


\section{References}

Araki, T. (1994) A physical model of geomagnetic sudden commencement, in Solar Wind Sources of Magnetospheric Ultra-Low-Frequency Waves. Geophys. Monogr. Ser., vol. 81, edited by M. J. Engebretson, K. Takahashi and M. Scholer, AGU, Washington, D. C., 183-200.

Bartels, J. (1932) Terrestrial magnetic activity and its relation to solar phenomena. Terr. Magn. Atmos. Elect. 37, 1-52.

Chen, L., and Hasegawa, A. (1974) A theory of long-period magnetic pulsations: 1. Steady state excitation of field line resonance. J. Geophys. Res., 79, 1024-1037.

Kikuchi, T., and Araki, T. (1979) Horizontal transmission of the polar electric field to the equator. $J$. Atmos. Terr. Phys., 41, 927-936.

Motoba, T., Kikuchi, T., Lühr, H., Tachihara, H., Kitamura, T.-I. Hayashi, K., and Okuzawa1 T. (2002) Global Pc5 caused by a DP 2-type ionospheric current system. J. Geophys. Res., 107 (A2), 1032-1014.

Ogunade. S. O. (1987) Geomagnetic variations in South-Western Nigeria Preliminary results. Ann. Geophys., 6, 607-611.

Priester, W., and D. Cattani, (1962) On the Semiannual Variation of Geomagnetic Activity and its Relation to the Solar Corpuscular Radiation. J. Atmos. Sci., 19, 121-126.

Rao, D. R. K., and Gupta, J. C. (1987) Some features of Pc5 pulsations during a solar cycle. Planet. Space Sci., 26, 1-20.

Reddy, C. A., Ravindran, S., Viswanathan, K. S., Krishna Murthy, B. V., Rao, D. R. K., and Araki, T. (1994) Observations of Pc5 micropulsation-related electric field oscillations in the equatorial ionosphere. Ann. Geophys., 12, 565-573.

Russell, C. T., and McPherron, R. L. (1973) Semiannual variation of geomagnetic activity Semiannual. J. Geophys. Res., 78, 92-108.

Saito, T. (1969) Geomagnetic Pulsations. Space Science Reviews, 10, 319-412.

Samson, J. C., Harrold, B. G., Ruohoniemi, J. M., and Walker, A. D. M. (1992) Field line resonances associated with MHD waveguides in the magnetosphere. Geophys. Res. Lett., 19, 441-444.

Southwood, D. J. (1974) Some features of field line resonances in the magnetosphere. Planet. Space Sci., 22(3), 483-491.

Southwood, D. J., Dungey, J. W. and Etherington, R. L. (1969) Bounce resonant interaction between pulsations and trapped particles. Planet. Space Sci., 17(3), 349-361.

Trivedi, N. B., Arora, B. R., Padilha, A. L., Da Costa, J. M., Dutra, S. L., Chamalaun, F. H., and Rigoti, A. (1997) Global Pc5 geomagnetic pulsations of March 24, 1991, as observed along the American sector, Geophys. Res. Lett., 24, 1683-1686.

Ziesolleck, C. W. S., and Chamalaun, F. H. A. (1993) A two dimensional array study of low-latitude Pc5 geomagnetic pulsations. J. Geophys. Res., 98, 13705-13713. 